\title{
IMPORTÂNCIA DO TRATAMENTO INDIVIDUALIZADO DA CRIANÇA INTERNA. FICHA DE ADMISSÃO
}

\author{
Leda Carvalho de Faria* \\ Rosa Alba de Oliveira Lima Cavalcanti** \\ Hilda Santana de Abreu***
}

RBEn/01

FARIA, L.C., colaboradores. - Importância do tratamento individualizado da criança. Ficha de admissão, Rev. Bras. de Enf., RJ, 28 : 7-10, 1975.

A internação de crianças ocometidas de doenças graves ou relativamente complexas vem se tornando cada vez mais imperiosa, sobretudo nos grandes centros urbanos, onde os múltiplos encargos e afazeres dos indivíduos impedem que os membros de uma família dediquem a devida atenção e assistência àquele, dentre eles, que exige cuidados médicos e de enfermagem. A necessidade da internação mostra-se ainda mais imperiosa quando o paciente é uma criança. Nesse caso, a prestação de cuidados requer atenção e zelo ainda maiores.

A internação de uma criança enferma oferece à sua família conforto, tranquilidade e segurança, permitindo a cada um dos membros do grupo familiar desempenhar suas atividades normais sem grandes transtornos. Ao mesmo tempo, embora possam ter motivos para preocupar-se com o estado da criança, a certeza de que esta se encontra sob competente e constante assistência constitui motivo de alívio.

Não obstante, o fato da internação pode provocar severo "stress" na criança enferma e, em seus familiares, sobretudo nos pais, ansiedade, sentimento de culpa e excesso de preocupação. A equipe de saúde deve, pois, atentar para as condições biopsicossociais tanto da criança como dos seus familiares e agir como elemento mediador e atenuante das emoções e sentimentos negativos decorrentes da doença e da internação.

A criança pode sentir a doença como uma agressão e sua separação da família, pela internação, como uma atitude de desestima ou abandono da parte dos pais. Daí a necessidade de considerarse a individualidade própria de cada criança e de toda equipe de saúde conhecer sua situação no grupo familiar. O conhecimento individualizado da criança não pode ficar ao capricho da simples intuição ou dos sentimentos afe-

* Enfermeira Chefe da Seção de Enfermagem Médica do H.S.P.E. - SP.

** Enfermeira Encarregada do Setor Enfermagem Pediátrica do H.S.P.E. - SP.

*** Enfermeira do Setor de Enfermagem Pediátrica do H.S.P.E. - SP. 
FARIA, L.C., colaboradores. - Importância do tratamento individualizado da criança. Ficha de admissão, Rev. Bras. de Enf., RJ, 28 : 7-10, 1975.

tivos de cada um, mas supõe, pelo menos, noções elementares de psicologia do desenvolvimento e de micro-sociologia, ou seja, da vida em grupo e dos processos de interação social.

E de fundamental importância a preparação da criança, sobretudo por meio do diálogo com os pais ou membros representativos da família. Em conversa com os pais deve-se procurar mostrar que a internação, desde que necessária, de acordo com o diagnóstico e o tratamento, é conveniente e benéfico para a criança e para eles próprios, dadas as condições da vida moderna e as vantagens que o tratamento hospitalar adequado pode proporcionar. Importa deixar claro também que a internação não deve implicar num rompimento da integração do grupo familiar, uma vez que o hospital moderno, através de técnicas apropriadas, zela pelo ajustamento da criança à nova situação, criando condições favoráveis à continuidade do seu processo evolutivo e dando aos familiares a oportunidade de manter o relacionamento afetivo com a mesma, o que é muito importante para seu restabelecimento físico, ajudando a evitar a situação de "stress" prejudicial ao tratamento.
O Setor de Enfermagem Pediátrica do H.S.P.E. de São Paulo vem se dedicando a estudos específicos sobre o tema relatado e através de treinamento e de grupos de estudos prepara sua equipe para dispensar à criança internada a melhor assistência possível.

A ficha de admissão, cujo modelo apresentamos, foi elaborada por uma equipe de trabalho que selecionou os elementos julgados essenciais à prestação de uma boa assistência de Enfermagem Pediátrica à criança, levando em conta sua situação no grupo familiar. A luz dessa ficha, da observação e de conversas posteriores com os pais e com a criança, as peculiaridades desta serão convenientemente valorizadas, tornando-se fácil conduzir os processos da individualização para uma assistência hospitalar adequada, de acordo com o diagnóstico, o tratamento e o desenvolvimento biopsicossocial.

São cinco os itens que constam da Ficha de Admissão: 1 - Identificação; 2 - Dados da admissão; 3 - Características pessoais; $4-$ Aspecto físico e 5 - Informações especiais, segundo o modelo abaixo reproduzido.

\section{REFERENCIAS BIBLIOGRAFICAS}

1 - Alcantara, Pedro - Pediatria Básica, Sarvier, São Paulo, 1968.

2 - COSTA, Lucimar de Oliveira Lima Socioterapia, Profissionalização e Autonomia do Serviço Social, Editora Vozes Ltda., Petrópolis, RJ, 1973.

3 - NEILL, A.S. - Liberdade sem Medo, Tradução de Nair Lacerda, 2. edição, São Paulo, IBRASA.
4 - ROCHA, Dulce Neves da - Elementos Básicos de Assistência de Enfermagem Pediátrica, Coleção Servir, Tomo II, Volume I, jun., 1971.

5 - SPITZ, Renée - O Desenvolvimento Emocional do Recém-nascido, Livraria Pioneira Editora, 1960.

6 - TOFFER, Alvin - O Choque do Futuro - Editora Artenova S.A., GB, 1973. 


\section{I — IDENTIFICAÇÃO}

NOME

Apelido.

Rg........

Quarto........ Leito

Idade ...

Cor.

Batizada........... Outras crianças em casa?

N. ${ }^{\circ}$. Idades.......... Pais vivos?

Nome do Pai Idade Prof...... Rel

Nome da Mãe Idade

Prof...... Rel....

Vivem juntos?

Endereço

Fone........

No caso de a mãe trabalhar fora, quem fica com a criança?

\section{II - DADOS DA ADMISSÃO}

Suspeita diagnostica:

hora de admissão ........ data.

Proced.

Já esteve hospitalizada?

Apresentou algum problema espe-

cial em relação à internação?

Já fez alguma cirurgia?... ....Sabe porque está internada?

O que lhe foi dito?

Qual a sua reação?

Dados vitais: $\mathrm{T}$ :

P: Pe:

PA: Estat:

\section{III - CARACTERisticas PESSOAIS}

\section{1 - Atividades lúdicas}

Brinca sozinha?..... Com outras crianças?..... Com adultos?..... Brinquedos prediletos:

\section{2 - Linguagem}

Já fala?. .... Idade a qual começou a falar:

Tem boa expressão oral?.

3 - Comunicação

Faz contato fácil com estranhos? .........Relacionamento individual ........... Relacionamento com o grupo .................

4 - Hábitos de Sono

Dorme em cama sozinha?.... Algum hábito especial para adormecer? ..... Faz orações?..... Faz sesta diariamente?...... Em que horário?..... ,

\section{5 - Controle Esfincteriano}

Fecal...... uretal...... enurese noturna......

Horário habitual para defecar.

Qual a palavra usada para defecar?...........

Para urinar? 


\section{6 - Hábitos de Higiene Pessoal}

Sabe tomar banho sozinha?..... Vestir-se?..... Pentear-se?...... Escovar os dentes?...... Precisa de ajuda para................

7 - Escolaridade

Freqüenta alguma instituição (creche, escola maternal, jardim de infância, etc.)?

\section{8 - Hábitos Alimentares}

Tipo de alimentação

Sabe comer sozinha?. ... Mamadeira?.... Colher?.... Copo?.....

\section{IV - ASPECTO FISICO}

Higiene pessoal.......... Condições da pele.......... Defeitos físicos .......... Couro cabelulo. ......... Olhos......... Nariz......... Boca......... Dentes.......... Orgãos genitais

\section{V — INFORMAÇÕES ESPECIAIS}

Usa chupeta..... Chupa o dedo?..... Usa fraldas?..... Está tomando alguma medicação?..... Aceita bem?..... Já recebeu soro por veia?.... Tem alguma fobia?..... Alergias.

Está fazendo algum tratamento ambulatorial?.......... Tem alguma consulta marcada?

Problemas identificados 